\title{
Penetrating injury to the right side of the heart without hemodynamic compromise
}

\author{
Zeljko Duric, MD, ${ }^{\mathrm{a}}$ Igor Gosev, $\mathrm{MD},{ }^{\mathrm{b}}$ and Drazen Belina, $\mathrm{MD}^{\mathrm{a}}$
}

We report the case of a 45-year-old man who attempted suicide with a kitchen knife. The knife (blade length, $20 \mathrm{~cm}$; blade width, $4 \mathrm{~cm}$ ) penetrated the anterior thoracic wall through the sternum and stayed fixed within the right ventricular cavity.

On his arrival at the emergency department, approximately 45 minutes after the injury, the patient was alert, oriented, and in hemodynamically stable condition. The patient's blood pressure was 130/90 mm Hg, his hemoglobin level was $161 \mathrm{~g} / \mathrm{L}$, and the electrocardiogram showed normal sinus rhythm with no identifiable ischemic changes or conduction abnormalities.

The knife was firmly stuck in the midline of the sternal body $2 \mathrm{~cm}$ above the xiphoid process and was not amenable to light movement. A computed tomographic scan revealed that the knife had penetrated the sternum, pericardium, and free right ventricular wall, with the tip of the knife penetrating $20 \mathrm{~mm}$ into the right ventricular cavity just below the tricuspid valve. The computed tomographic scan further demonstrated a lamellar pericardial effusion, with clot in the anterior mediastinum (Figures 1 and 2).

The patient was transferred to the operating room for emergency surgery (Figure 3). His hemodynamic condition remained stable throughout the process, with a central venous pressure of $8 \mathrm{~mm} \mathrm{Hg}$ at the time of anesthetic induction.

Intraoperative transesophageal echocardiography showed only a very small pericardial effusion. It also confirmed that the tip of the knife was in the right ventricular cavity without injury to the tricuspid valve.

The patient was fully heparinized, and then cardiopulmonary bypass was instituted through the femoral vessels. Once cardiopulmonary bypass had been established, the knife was pulled out of the sternum. A median sternotomy

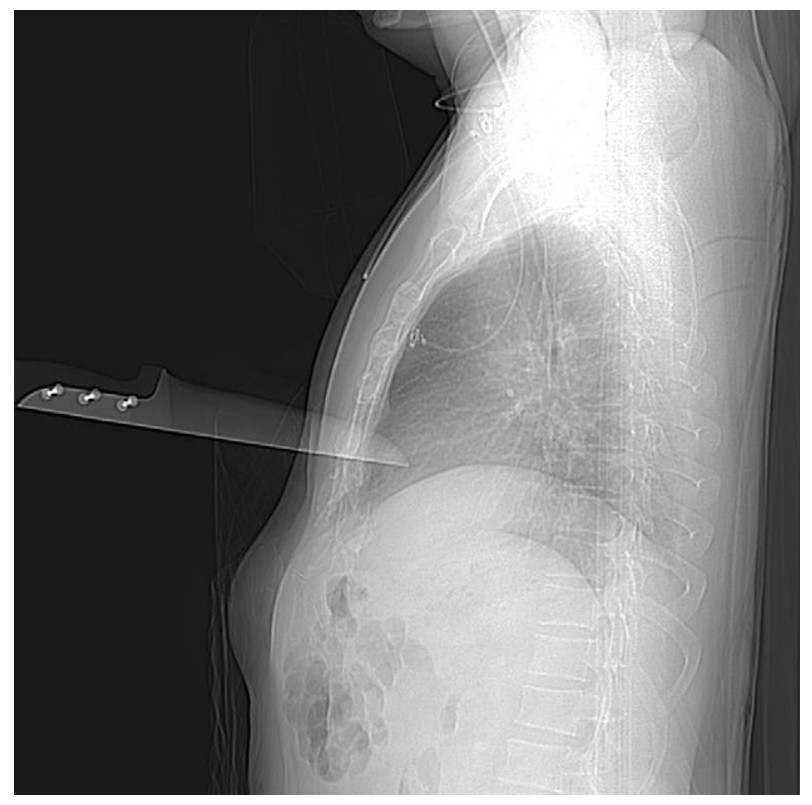

FIGURE 1. Multislice computed tomographic scan topogram.

was then immediately performed. When the pericardium was opened, only a minimal amount of blood was seen. An entry wound $20 \mathrm{~mm}$ long was found over the anterior aspect of the right ventricular outflow tract. Direct primary repair was achieved with 2 polytetrafluoroethylene-pledgeted 4-0 polypropylene sutures.

The patient was weaned from cardiopulmonary bypass without difficulty. The postoperative transesophageal echocardiogram showed no pathologic substrate.

Débridement of the entry wound on the chest was accomplished by excision of the soft tissue. The patient made an uneventful recovery and was discharged from the cardiac surgical service on the fourth postoperative day.

\footnotetext{
From the Department of Cardiac Surgery, ${ }^{a}$ University Hospital Zagreb, Zagreb, Cro-

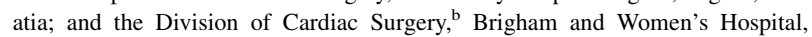
Boston, Mass.

Received for publication March 11, 2012; accepted for publication March 19, 2012; available ahead of print April 16, 2012.

Address for reprints: Igor Gosev, MD, Department of Cardiac Surgery, Brigham and Women’s Hospital, 75 Frances St, Boston, MA 02115 (E-mail: igosev@partners. org).

J Thorac Cardiovasc Surg 2012;144:263-4

$0022-5223 / \$ 36.00$

Copyright (c) 2012 by The American Association for Thoracic Surgery

doi:10.1016/j.jtcvs.2012.03.053
} 

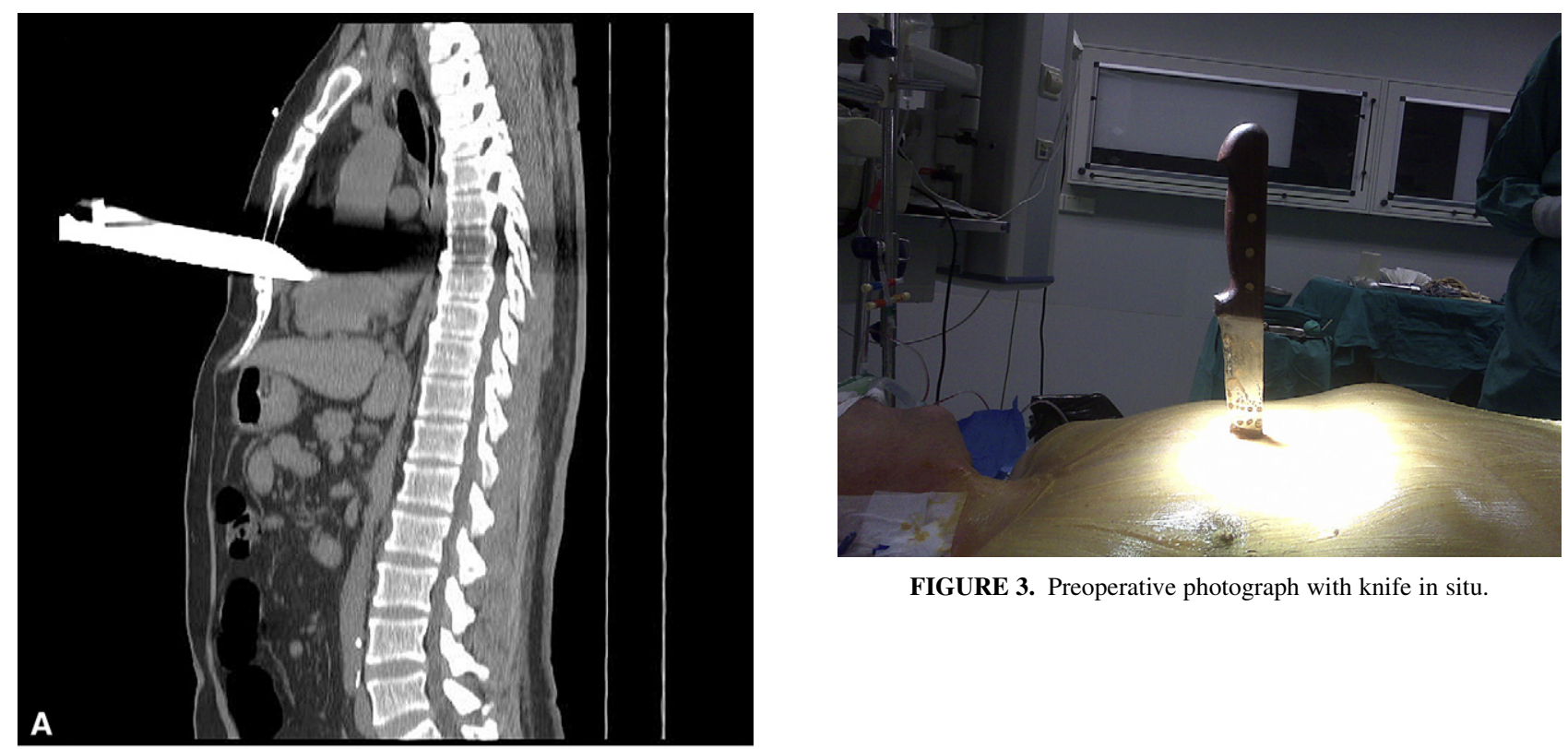

FIGURE 3. Preoperative photograph with knife in situ.

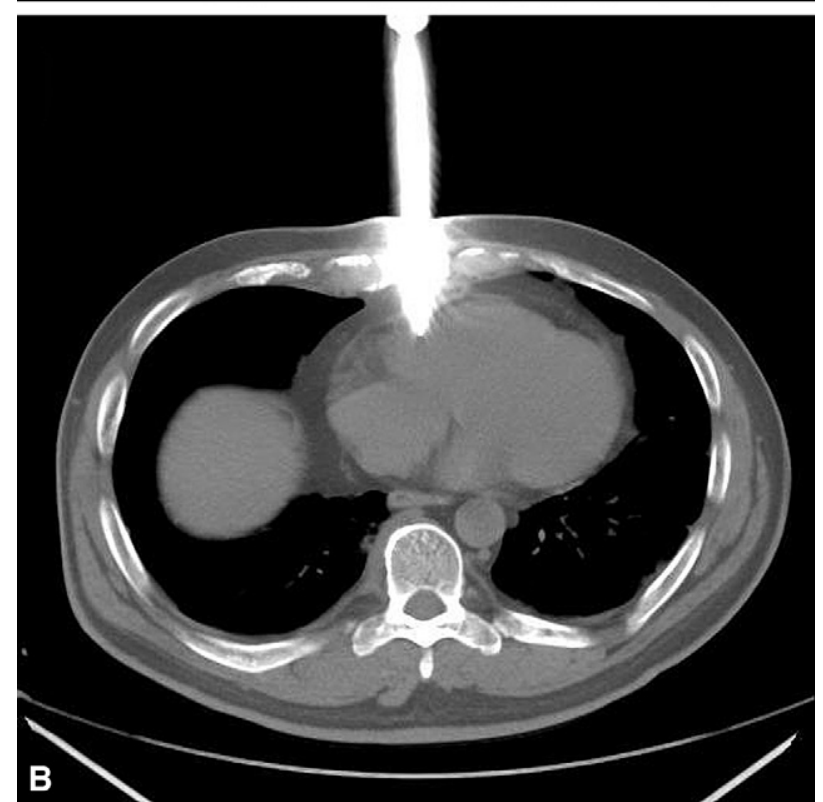

FIGURE 2. Multislice computed tomographic scans, (A) sagital and (B) transverse, showing lamellar pericardial effusion and knife penetrating the right ventricle. 